\title{
DSM-IV Personality Disorders and Their Axis I Correlates in the South African Population
}

\author{
S. Suliman ${ }^{a}$ D.J.Stein ${ }^{\text {a, b }}$ D.R. Williams ${ }^{c} \quad$ S. Seedat ${ }^{a}$ \\ ${ }^{a}$ MRC Anxiety and Stress Disorders Unit, Department of Psychiatry, University of Stellenbosch, and ${ }^{b}$ Department of \\ Psychiatry, University of Cape Town, Cape Town, South Africa; ' ${ }^{C H a r v a r d ~ S c h o o l ~ o f ~ P u b l i c ~ H e a l t h, ~ B o s t o n, ~ M a s s ., ~ U S A ~}$
}

\section{Key Words}

Diagnostic and Statistical Manual of Mental Disorders, axis I disorders $\cdot$ Personality disorders, prevalence $\cdot$ South Africa

\begin{abstract}
Background: The prevalence of personality disorders (PD) in the South African population is largely unknown. Thus, we undertook to estimate prevalence, demographic correlates, co-morbidity and treatment rates of DSM-IV PD among South Africans. Sampling and Methods: A three-stage probability sample design was used. Of the 4,433 interviews obtained, based on quality control criteria, 4,315 interviews were retained for analysis. All participants were screened for PD and axis I disorders with the World Health Organisation Composite International Diagnostic Interview. The multiple imputation method was then used to estimate prevalence. Results: The multiple imputation prevalence estimate in the total sample was $6.8 \%$. All three PD clusters were significantly co-morbid with each other and with other axis I disorders. Male gender was the only significant predictor of PD. Of note was the finding that less than one fifth of participants with a possible PD diagnosis had received treatment for a mental health or substance abuse problem in the previous 12 months. Conclusion: The high co-morbidity of PD with axis I disorders in South Africa is consistent with previous reports
\end{abstract}

elsewhere. However, more research is indicated to determine the reasons for the higher prevalence of cluster A disorders than of cluster $B$ and $C$ disorders in this population.

Copyright $\odot 2008$ S. Karger AG, Basel

\section{Introduction}

Personality disorders (PD) are amongst the most prevalent of psychiatric disorders, and they frequently co-occur with one another as well as with other psychiatric disorders $[1,2]$, in particular with DSM-IV axis I disorders $[3,4]$. PD have been associated with a number of adverse consequences in the general population, including marital problems, occupational difficulties, criminality [5-7] and the high use of costly mental health services [8]. As such, they are associated with a significant burden, not only on the individual with the disorder, but on society at large. Furthermore, they are related to poorer outcomes in patients with other psychiatric and substance use disorders $[9,10]$. Despite this, they are underresearched compared to other mental health problems [1113].

Most studies assessing prevalence rates of PD have focused on clinical populations [14-16]. Lenzenweger et al. [17] presented the first high-quality estimate of $\mathrm{PD}$ in a

S. Suliman

MRC Unit on Anxiety and Stress Disorders, Department of Psychiatry

PO Box 19063, Tygerberg, 7505

Cape Town (South Africa)

Tel. +27 21938 9020, Fax +27 21933 5790, E-Mail sharain@sun.ac.za 
non-clinical population (11\%). Since then, a number of studies have attempted to determine prevalence rates in community samples. In the United States, community prevalence rates ranging from $9 \%[18,19]$ to $15.7 \%$ [20] have been found. Similarly, in Europe, rates of $10.0 \%$ in Germany [21], 11.2\% in Sweden [22] and 13.4\% in Norway [23] have been documented. Comparatively lower rates have been reported in Britain (4.4\%) by Coid et al. [24] and in Australia (6.6\%) [25]. These differences could in part be explained by the use of different study methodologies and measures. For example, in the US, a rate of $9 \%$ was reported by both studies using the International Personality Disorders Examination (IPDE) [18, 19], whereas the study by Crawford et al. [20] used the Structured Clinical Interview for DSM-IV (SCID-II) to make a PD diagnosis.

There have been few reports of rates of PD in low- and middle-income countries. For example, a $6.7 \%$ prevalence was found in a group of normal Brazilian controls [26], while the prevalence of personality dysfunction in a study of senior high school students in Beijing was found to be $5.6 \%$ [27]. In a sample of Egyptian university students, more than a quarter $(26.1 \%)$ were found to have at least 1 PD [28]. Although the latter 2 studies both used translated versions of the Personality Diagnostic Questionnaire, the student samples differed, e.g. in respect of age. Thus, again these differences may potentially be explained by methodological differences.

Nonetheless, the epidemiological investigation of PD in South Africa and Africa as a whole has largely been neglected. The South African Stress and Health Study (SASH) was a national probability sample of adult South Africans living in both households and hostel quarters, with data obtained between January 2002 and June 2004 [29]. This provided an opportunity to estimate the prevalence of PD in the South African population. The aims of this study were to: (1) estimate the prevalence of DSM-IV PD; (2) examine demographic correlates of PD; (3) assess co-morbidity with axis I disorders; (4) estimate treatment rates for DSM-IV PD in this population.

\section{Methods}

\section{Sample}

Full details of the sampling are provided in a previous paper [29]. In brief, individuals of all racial and ethnic backgrounds were included in the study. Hostel quarters were included to maximize coverage of young working-age males, but the sample did not include individuals in institutions or in the military. The sample was selected using a three-stage probability sample design.
Table 1. Sociodemographic distribution of the South African sample compared to the population

\begin{tabular}{|c|c|c|c|}
\hline & $\begin{array}{l}\text { Unweighted } \\
\%\end{array}$ & $\begin{array}{l}\text { Weighted } \\
\%\end{array}$ & $\begin{array}{l}2001 \text { census } \\
\%\end{array}$ \\
\hline \multicolumn{4}{|l|}{ Sex } \\
\hline Male & 39.8 & 46.3 & 46.8 \\
\hline Female & 60.2 & 53.7 & 53.2 \\
\hline \multicolumn{4}{|l|}{ Age } \\
\hline $20-34$ & 47.1 & 47.2 & 45.5 \\
\hline $35-49$ & 31.2 & 30.4 & 30.5 \\
\hline $50-64$ & 15.8 & 16.9 & 15.3 \\
\hline $65+$ & 5.9 & 5.5 & 8.7 \\
\hline \multicolumn{4}{|l|}{ Race } \\
\hline African & 76.2 & 76.2 & 79.0 \\
\hline Coloured & 12.9 & 10.4 & 8.9 \\
\hline Indian or Asian & 3.7 & 3.4 & 2.5 \\
\hline White & 7.2 & 10.0 & 9.6 \\
\hline \multicolumn{4}{|l|}{ Province } \\
\hline Eastern Cape & 14.2 & 13.1 & 13.3 \\
\hline Free State & 9.7 & 6.2 & 6.2 \\
\hline Guateng & 13.6 & 23.0 & 22.2 \\
\hline Kwazulu Natal & 17.2 & 19.5 & 20.2 \\
\hline Limpopo & 9.6 & 10.5 & 10.5 \\
\hline Mpumalanga & 9.5 & 6.6 & 6.6 \\
\hline Northern Cape & 5.4 & 1.9 & 1.3 \\
\hline North West & 10.4 & 8.3 & 8.3 \\
\hline Western Cape & 10.3 & 11.1 & 10.8 \\
\hline
\end{tabular}

The first stage involved selecting a stratified probability sample of primary sampling areas equivalent to counties in the US or the UK based on the 2001 South African Census of Enumeration Areas (EA). The EA were sampled with probabilities proportionate to population size. The second stage involved selecting an equalprobability sample of housing units within each EA. The third stage involved selecting one random adult respondent from each sample housing unit. Interviewers selected a single adult respondent at random using the Kish procedure for objective respondent selection [30]. A total sample of 5,089 households was selected for SASH. Field interviews were obtained with 4,433 (87.1\%) of the designated respondents. Based on quality control criteria, 4,315 of the field interviews were retained for use in the analysis. Table 1 displays the sociodemographic distribution of the sample.

\section{Diagnostic Interview}

The diagnostic interview used in the SASH was the World Health Organization (WHO) Composite International Diagnostic Interview version 3.0 (CIDI) [31], a fully structured lay-administered interview that generates diagnoses according to the criteria of both the DSM-IV and the ICD-10 diagnostic systems. In view of time constraints, however, the interview excluded a number of disorders (e.g. specific phobia, impulse control disorders other than intermittent explosive disorder). DSM-IV criteria are used in the current report. Interviewers were trained in the administration of the CIDI in centralized group sessions lasting one 
Table 2. Prevalence of PD

\begin{tabular}{|c|c|c|c|c|c|c|c|c|}
\hline \multirow{2}{*}{$\begin{array}{l}\text { Personality } \\
\text { disorder }\end{array}$} & \multirow{2}{*}{$\begin{array}{l}\text { Sample } \\
\text { size }\end{array}$} & \multicolumn{5}{|c|}{ Basic statistics for number of cases with disorder in $10 \mathrm{MI}$ data sets } & \multicolumn{2}{|l|}{ Prevalence } \\
\hline & & average & SD & $\mathrm{CV}$ & minimum & maximum & estimate, \% & SE \\
\hline Cluster A & 4,315 & 137.6 & 16.4 & 11.9 & 112.0 & 170.0 & 3.4 & 0.5 \\
\hline Cluster B & 4,315 & 58.6 & 7.9 & 13.5 & 47.0 & 75.0 & 1.5 & 0.3 \\
\hline Cluster C & 4,315 & 102.9 & 12.3 & 11.9 & 79.0 & 123.0 & 2.5 & 0.5 \\
\hline Any & 4,315 & 272.3 & 22.6 & 8.3 & 247.0 & 317.0 & 6.8 & 0.7 \\
\hline
\end{tabular}

$\mathrm{CV}=$ Coefficient of variation .

Table 3. Odds of other PD

\begin{tabular}{llllll}
\hline $\begin{array}{lllll}\text { Personality } \\
\text { cluster }\end{array}$ & \multicolumn{2}{l}{ Cluster B } & & \multicolumn{2}{l}{ Cluster C } \\
\cline { 2 - 3 } \cline { 5 - 6 } & OR & $95 \%$ CI & & OR & $95 \%$ CI \\
\hline Cluster A & $21.5^{*}$ & $7.2,64.9$ & & $13.1^{*}$ & $4.5,38.6$ \\
Cluster B & & & & $11.0^{*}$ & $3.0,40.5$ \\
\hline
\end{tabular}

Results represent odds of having multiple-cluster disorders. Models were not adjusted for sociodemographic effects.

* Significant at the 0.05 level.

week. The interviews were conducted face-to-face in six different languages: English, Afrikaans, Zulu, Xhosa, Northern Sotho and Tswana. The protocol, including all recruitment, consent and field procedures, were approved by the Human Subjects Committees of the University of Michigan, Harvard Medical School, and by a single-project assurance of compliance from the Medical University of South Africa that was approved by the National Institute of Mental Health. Interviews lasted an average of three and a half hours, with some requiring more than one visit to complete.

\section{Statistical Analysis}

The person-level SASH data was weighted to adjust for differential probabilities of selection within households, differential non-response, and for residual discrepancies between the sample and the population on a profile of census demographic and geographic variables. These weights were used in all data analyses. Data analysis was carried out using SAS and SAS-callable SUDAAN software to adjust estimates of statistical significance for the weighting and clustering of the data. Statistical methods include standard estimates of prevalence, and the calculation of odds ratios (OR). Statistical significance was evaluated using 0.05-level two-sided tests, which adjusted for the weighting and clustering of the data.

In the World Mental Health (WMH) United States survey (NCS-R), clinical reappraisal interviews with the IPDE were carried out with a probability subsample of 214 respondents, oversampling those who screened positive on the IPDE screening questions. The data were weighted to adjust for this oversampling. DSM-IV diagnoses based on the clinical interviews were generated for any cluster A PD, any cluster B PD, any cluster C PD and any PD (including PD not otherwise specified, which was not included in any of the three clusters). Ten clinical pseudo samples were created using the US validity sample by selecting 214 cases for each sample with replacements from the 214 cases in the clinical sample. Predicted probabilities of the four IPDE diagnoses were assigned, based on the results of stepwise logistic regression in each of these 10 samples. The multiple imputation (MI) method was used to assign predicted diagnoses of clinician-assessed IPDE diagnoses to WMH respondents, including SASH respondents, who did not participate in the reappraisal interviews [32]. Prediction accuracy was excellent for all four of these equations in the South African sample, with area under the receiver operator characteristic curve (AUC), a prevalence-free measure of classification accuracy, 0.9396 for cluster A, 0.9572 for cluster B, 0.8971 for cluster $\mathrm{C}$ and 0.8808 for any PD.

\section{Results}

\section{Prevalence of Personality Disorders}

The prevalence estimate for any personality disorder was $6.8 \%(\mathrm{SE}=0.7)$, and $3.4 \%(\mathrm{SE}=0.5), 1.5 \%(\mathrm{SE}=0.3)$ and $2.5 \%(\mathrm{SE}=0.5)$ for cluster $\mathrm{A}, \mathrm{B}$ and $\mathrm{C}$ personality disorders, respectively (table 2).

\section{Co-Morbidity}

In addition, for those with any personality disorder, the odds of having a personality disorder from another cluster were significant (table 3 ). There was a significant association of cluster B PD with cluster A PD (OR = 21.5; 95\% CI $=7.2,64.9$ ), cluster $\mathrm{C} P D$ with cluster A PD $(\mathrm{OR}=13.1 ; 95 \% \mathrm{CI}=4.5,38.6)$ and cluster $\mathrm{C} \mathrm{PD}$ with cluster B $(\mathrm{OR}=11.0 ; 95 \% \mathrm{CI}=3.0,40.5)$.

All PD were associated with DSM-IV axis 1 disorders with the mean OR as follows: cluster A: 3.06 , cluster B: 7.83, and cluster C: 4.96 , and medians of $2.65,10.60$ and 
Table 4. Comorbidity with DSM-IV 12-month disorders

\begin{tabular}{|c|c|c|c|c|c|c|c|c|c|}
\hline \multirow{2}{*}{$\begin{array}{l}\text { Disorder } \\
\text { group }\end{array}$} & \multirow[t]{2}{*}{ 12-month disorder } & \multicolumn{2}{|c|}{ Cluster A } & \multicolumn{2}{|c|}{ Cluster B } & \multicolumn{2}{|c|}{ Cluster C } & \multicolumn{2}{|l|}{ Any } \\
\hline & & OR & $95 \% \mathrm{CI}$ & OR & $95 \% \mathrm{CI}$ & OR & $95 \% \mathrm{CI}$ & OR & $95 \% \mathrm{CI}$ \\
\hline Anxiety & any anxiety disorder & $4.4^{*}$ & $1.8,11.0$ & $8.2^{*}$ & $3.5,18.8$ & $5.9^{*}$ & $2.2,15.6$ & $5.7^{*}$ & $3.3,9.7$ \\
\hline Mood & any mood disorder & 2.0 & $0.6,6.6$ & 2.3 & $0.6,8.6$ & $5.3^{*}$ & $2.2,12.5$ & $4.4^{*}$ & $1.9,10.4$ \\
\hline Impulse & any impulse disorder & 2.8 & $0.4,17.6$ & $13.0^{*}$ & $3.4,49.5$ & 3.7 & $0.6,22.5$ & $3.6^{*}$ & $1.0,12.7$ \\
\hline Substance & any substance disorder & $2.5^{*}$ & $1.0,5.9$ & $20.9^{*}$ & $6.7,64.8$ & 1.8 & $0.3,11.2$ & $2.7^{*}$ & $1.1,7.1$ \\
\hline \multirow[t]{4}{*}{ Composite } & exactly one & $3.0^{*}$ & $1.3,6.9$ & $9.9^{*}$ & $3.2,30.3$ & $3.6^{*}$ & $1.6,8.2$ & $3.3^{*}$ & $1.9,5.6$ \\
\hline & exactly two & $3.7^{*}$ & $1.1,12.3$ & $25.5^{*}$ & $7.3,89.0$ & $7.1^{*}$ & $2.0,24.9$ & $5.7^{*}$ & $2.2,14.7$ \\
\hline & three or more & 3.7 & $0.3,53.5$ & $47.8^{*}$ & $9.4,242.5$ & $8.0^{*}$ & $1.1,56.1$ & n.a. & n.a. \\
\hline & any disorder & $3.2^{*}$ & $1.6,6.6$ & $15.2^{*}$ & $5.5,42.0$ & $4.7^{*}$ & $2.3,9.5$ & $4.2^{*}$ & $2.5,7.1$ \\
\hline
\end{tabular}

OR based on logistic regression models adjusted for age and sex. Exactly one, exactly two, and three or more fit together in a single model. Any anxiety, mood, impulse, substance and any disorder fit in separate models.

* Significant at the 0.05 level; n.a. = results unavailable due to lack of cases with both personality and DSM-IV disorders.

Table 5. Conditional prevalence with DSM-IV 12-month disorders

\begin{tabular}{|c|c|c|c|c|c|c|c|c|c|c|c|c|c|c|c|c|c|}
\hline \multirow{2}{*}{$\begin{array}{l}\text { Disorder } \\
\text { group }\end{array}$} & \multirow{2}{*}{$\begin{array}{l}\text { 12-month } \\
\text { disorder }\end{array}$} & \multicolumn{4}{|c|}{ Cluster A } & \multicolumn{4}{|c|}{ Cluster B } & \multicolumn{4}{|c|}{ Cluster C } & \multicolumn{4}{|l|}{ Any } \\
\hline & & $\begin{array}{l}\text { row } \\
\%\end{array}$ & $\begin{array}{l}\text { row } \\
\text { SE }\end{array}$ & $\begin{array}{l}\text { column } \\
\%\end{array}$ & $\begin{array}{l}\text { column } \\
\text { SE }\end{array}$ & $\begin{array}{l}\text { row } \\
\%\end{array}$ & $\begin{array}{l}\text { row } \\
\text { SE }\end{array}$ & $\begin{array}{l}\text { column } \\
\%\end{array}$ & $\begin{array}{l}\text { column } \\
\text { SE }\end{array}$ & $\begin{array}{l}\text { row } \\
\%\end{array}$ & $\begin{array}{l}\text { row } \\
\text { SE }\end{array}$ & $\begin{array}{l}\text { column } \\
\%\end{array}$ & $\begin{array}{l}\text { column } \\
\text { SE }\end{array}$ & $\begin{array}{l}\text { row } \\
\%\end{array}$ & $\begin{array}{l}\text { row } \\
\text { SE }\end{array}$ & $\begin{array}{l}\text { column } \\
\%\end{array}$ & $\begin{array}{l}\text { column } \\
\text { SE }\end{array}$ \\
\hline Anxiety & $\begin{array}{l}\text { any anxiety } \\
\text { disorder }\end{array}$ & 9.9 & 3.4 & 13.0 & 4.2 & 8.2 & 2.6 & 25.3 & 7.4 & 10.7 & 3.9 & 19.4 & 6.6 & 22.6 & 4.0 & 15.1 & 2.9 \\
\hline Mood & $\begin{array}{l}\text { any mood } \\
\text { disorder }\end{array}$ & 4.9 & 2.0 & 7.2 & 3.4 & 3.1 & 1.5 & 10.6 & 5.6 & 9.3 & 2.7 & 18.2 & 5.7 & 18.5 & 4.8 & 13.4 & 3.7 \\
\hline Impulse & $\begin{array}{l}\text { any impulse } \\
\text { disorder }\end{array}$ & 9.9 & 6.9 & 5.4 & 3.9 & 14.2 & 7.3 & 18.1 & 8.6 & 8.9 & 6.2 & 6.8 & 4.9 & 21.0 & 8.9 & 5.8 & 2.6 \\
\hline Substance & $\begin{array}{l}\text { any substance } \\
\text { disorder }\end{array}$ & 9.7 & 3.1 & 16.7 & 5.5 & 12.4 & 3.8 & 49.4 & 12.0 & 5.1 & 3.0 & 11.8 & 6.9 & 18.4 & 5.7 & 15.6 & 4.5 \\
\hline Composite & $\begin{array}{l}\text { exactly one } \\
\text { disorder } \\
\text { exactly two }\end{array}$ & 7.5 & 1.9 & 22.2 & 6.4 & 4.9 & 1.6 & 33.2 & 9.2 & 6.1 & 2.1 & 24.0 & 6.7 & 14.8 & 2.7 & 21.8 & 3.7 \\
\hline & $\begin{array}{l}\text { disorders } \\
\text { three or more }\end{array}$ & 9.5 & 4.2 & 8.6 & 3.9 & 11.8 & 4.9 & 24.9 & 9.6 & 11.2 & 5.1 & 13.7 & 5.8 & 23.2 & 6.5 & 10.5 & 3.2 \\
\hline & disorders & 9.9 & 9.7 & 2.1 & 2.0 & 20.3 & 9.6 & 10.4 & 5.4 & 11.9 & 8.3 & 3.7 & 2.9 & 35.8 & 13.5 & 4.0 & 1.6 \\
\hline & any disorder & 8.1 & 1.7 & 32.9 & 7.3 & 7.3 & 1.7 & 68.5 & 9.6 & 7.5 & 1.9 & 41.5 & 8.1 & 17.8 & 2.9 & 36.2 & 5.1 \\
\hline
\end{tabular}

Row percentages represent the amount of respondents with each axis I disorder who meet criteria for the PD. Column percentages represent the amount of respondents with the PD that meet criteria for the axis I disorder.

4.50 , respectively. Cluster A PD were significantly associated with substance use disorders, cluster B PD were significantly associated with impulse and substance use disorders and cluster C PD were significantly associated with mood disorders (table 4). All 3 clusters were significantly associated with anxiety disorders.
The range of OR with axis I disorders was quite narrow for clusters $A$ and $C$, suggesting that the strength of the associations for these PD with axis I disorders are similar. However, there was more differentiation in OR for cluster B, with any substance disorder having the highest and any mood disorder having the lowest OR. 
Table 6. Sociodemographic predictors

\begin{tabular}{|c|c|c|c|c|c|c|c|c|c|c|c|c|}
\hline \multirow[t]{2}{*}{ Sociodemographic predictor } & \multicolumn{3}{|c|}{ Cluster A } & \multicolumn{3}{|c|}{ Cluster B } & \multicolumn{3}{|c|}{ Cluster C } & \multicolumn{3}{|l|}{ Any } \\
\hline & OR & $95 \% \mathrm{CI}$ & $\mathrm{p}$ value & OR & $95 \% \mathrm{CI}$ & $\mathrm{p}$ value & OR & $95 \%$ CI & $\mathrm{p}$ value & OR & $95 \% \mathrm{CI}$ & $\mathrm{p}$ value \\
\hline Sex (female) & 0.2 & $0.1,0.4$ & 0.000 & 1.0 & $0.3,2.7$ & 0.942 & 0.6 & $0.2,1.6$ & 0.233 & 0.4 & $0.2,0.6$ & 0.000 \\
\hline Age (standardized) & 0.9 & $0.6,1.3$ & 0.537 & 0.8 & $0.5,1.4$ & 0.502 & 1.1 & $0.8,1.7$ & 0.505 & 0.9 & $0.7,1.2$ & 0.407 \\
\hline Education (standardized) & 0.8 & $0.5,1.1$ & 0.128 & 0.8 & $0.6,1.3$ & 0.408 & 0.8 & $0.6,1.2$ & 0.292 & 0.9 & $0.6,1.1$ & 0.222 \\
\hline Employment (other) & 1.0 & $0.5,1.9$ & 0.988 & 0.7 & $0.3,2.0$ & 0.537 & 0.9 & $0.3,2.6$ & 0.805 & 1.0 & $0.6,1.6$ & 0.996 \\
\hline Income (standardized) & 0.8 & $0.3,2.0$ & 0.546 & 1.0 & $0.6,1.6$ & 0.858 & 0.6 & $0.1,5.3$ & 0.587 & 0.8 & $0.5,1.5$ & 0.462 \\
\hline Marital status (not married) & 1.2 & $0.6,2.5$ & 0.539 & 1.7 & $0.6,4.9$ & 0.296 & 1.3 & $0.7,2.4$ & 0.457 & 1.3 & $0.8,2.2$ & 0.274 \\
\hline
\end{tabular}

Sociodemographic predictors fit simultaneously in a single model.

Table 7. Prevalence of 12 -month treatment among those with PD

\begin{tabular}{|c|c|c|c|c|c|c|c|c|}
\hline \multirow[t]{2}{*}{ Treatment sector } & \multicolumn{2}{|c|}{ Cluster A } & \multicolumn{2}{|c|}{ Cluster B } & \multicolumn{2}{|c|}{ Cluster C } & \multicolumn{2}{|l|}{ Any } \\
\hline & $\%$ & SE & $\%$ & SE & $\%$ & SE & $\%$ & SE \\
\hline Psychiatrist & 2.5 & 2.3 & 4.2 & 3.2 & 2.9 & 2.2 & 3.1 & 1.4 \\
\hline Other mental health & 1.7 & 1.7 & 1.7 & 2.0 & 1.1 & 1.3 & 2.1 & 1.3 \\
\hline Any mental health & 3.0 & 2.5 & 4.8 & 3.6 & 3.4 & 2.5 & 3.9 & 1.5 \\
\hline General medical & 14.7 & 4.8 & 12.7 & 6.3 & 15.1 & 5.4 & 13.4 & 2.9 \\
\hline Human service & 2.8 & 1.8 & 4.2 & 5.1 & 6.3 & 3.9 & 4.7 & 1.7 \\
\hline CAM & 3.9 & 3.1 & 2.7 & 3.2 & 6.0 & 3.9 & 4.7 & 2.4 \\
\hline Any treatment & 18.9 & 5.3 & 19.6 & 7.5 & 22.3 & 6.7 & 19.9 & 4.0 \\
\hline
\end{tabular}

Percentages represent respondents seeking treatment among those with personality disorder. CAM = Complementary and alternative medicine.

Patients with three or more disorders were more likely to have co-morbid anxiety disorders.

These high OR indicate that a large proportion of the population (36.2\%) with PD also meets the criteria for an axis I disorder (table 5). Cluster A and cluster B PD most commonly co-occur with substance disorders (16.7 and $49.4 \%$, respectively) followed by anxiety disorders ( 13 and $25.3 \%$, respectively). Cluster C PD most often co-occur with anxiety disorders (19.4\%), followed by mood disorders (18.2\%). Those with a cluster B PD were more likely than those with a cluster A or C PD to meet criteria for more than one axis I disorder. Approximately a quarter of individuals (24.9\%) with a cluster B PD met criteria for two axis I disorders and $10.4 \%$ met criteria for three or more axis I disorders.

The conditional prevalence of a PD was fairly similar for respondents with any anxiety disorder (22.6\%), any mood disorder (18.5\%), any impulse control disorder
(21.0\%) and any substance disorder (18.4\%). Respondents with three or more axis I disorders were more likely than those with fewer axis I disorders to be diagnosed with a PD.

\section{Sociodemographic Correlates of DSM-IV PD}

Sociodemographic predictors of $\mathrm{PD}$, including gender, age, education, employment, income and marital status, are shown in table 6. All, except gender, were nonsignificant, with male gender predicting cluster A PD $(\mathrm{OR}=0.2 ; 95 \% \mathrm{CI}=0.1,0.4)$ and any $\mathrm{PD}(\mathrm{OR}=0.4 ; 95 \%$ $\mathrm{CI}=0.2,0.6)$.

\section{Treatment}

Over the past 12 months, $19.9 \%$ of respondents with a PD had received treatment for mental health or substance use problems (table 7). The majority sought treatment from general medical providers rather than from mental 
Table 8. Odds of 12-month treatment

\begin{tabular}{|c|c|c|c|c|c|c|c|c|c|}
\hline \multirow[t]{2}{*}{ Model } & \multirow[t]{2}{*}{ Treatment sector } & \multicolumn{2}{|c|}{ Cluster A } & \multicolumn{2}{|c|}{ Cluster B } & \multicolumn{2}{|c|}{ Cluster C } & \multicolumn{2}{|l|}{ Any } \\
\hline & & odds & $95 \%$ CI & odds & $95 \% \mathrm{CI}$ & odds & $95 \% \mathrm{CI}$ & odds & $95 \% \mathrm{CI}$ \\
\hline \multirow[t]{7}{*}{ I } & Psychiatrist & 1.2 & $0.1,20.0$ & 2.4 & $0.3,20.0$ & 1.5 & $0.2,8.8$ & 2.0 & $0.6,6.3$ \\
\hline & Other mental health & 1.5 & $0.2,13.3$ & 1.2 & $0.1,13.7$ & 0.8 & $0.1,11.9$ & 1.9 & $0.4,8.7$ \\
\hline & Any mental health & 1.0 & $0.1,10.6$ & 1.8 & $0.2,16.5$ & 1.2 & $0.2,6.2$ & 1.8 & $0.7,4.4$ \\
\hline & General medical & 1.7 & $0.7,3.9$ & 1.3 & $0.4,4.2$ & 1.5 & $0.6,4.1$ & 1.5 & $0.9,2.6$ \\
\hline & Human service & 0.8 & $0.2,3.7$ & 0.8 & $0.0,29.3$ & 1.8 & $0.4,8.8$ & 1.5 & $0.7,3.3$ \\
\hline & CAM & 0.9 & $0.1,9.1$ & 0.6 & $0.0,7.2$ & 1.6 & $0.3,8.2$ & 1.3 & $0.4,4.6$ \\
\hline & Any treatment & 1.4 & $0.7,3.1$ & 1.4 & $0.5,3.7$ & 1.6 & $0.7,3.8$ & 1.5 & $0.9,2.6$ \\
\hline \multirow[t]{7}{*}{ II } & Psychiatrist & 0.9 & $0.0,16.3$ & 1.3 & $0.1,10.6$ & 1.0 & $0.2,6.1$ & 1.4 & $0.4,4.8$ \\
\hline & Other mental health & 1.0 & $0.1,9.6$ & 0.5 & $0.0,5.8$ & 0.5 & $0.0,7.1$ & 1.2 & $0.2,6.2$ \\
\hline & Any mental health & 0.8 & $0.1,8.5$ & 0.9 & $0.1,8.5$ & 0.8 & $0.2,4.2$ & 1.3 & $0.5,3.4$ \\
\hline & General medical & 1.5 & $0.6,3.6$ & 0.9 & $0.3,3.1$ & 1.3 & $0.5,3.5$ & 1.3 & $0.7,2.3$ \\
\hline & Human service & 0.7 & $0.2,3.2$ & 0.5 & $0.0,20.6$ & 1.4 & $0.3,6.9$ & 1.2 & $0.5,2.8$ \\
\hline & CAM & 0.8 & $0.1,8.4$ & 0.4 & $0.0,5.3$ & 1.3 & $0.2,6.9$ & 1.1 & $0.3,4.2$ \\
\hline & Any treatment & 1.2 & $0.5,2.8$ & 0.9 & $0.3,2.5$ & 1.3 & $0.5,3.1$ & 1.3 & $0.7,2.2$ \\
\hline
\end{tabular}

Results represent odds of treatment given each personality disorder. Separate models: model I adjusted for sex and age; model II adjusted for sex, age and any axis I disorder.

$\mathrm{CAM}=$ Complementary and alternative medicine. ${ }^{*}$ Significant at the 0.05 level.

health (i.e. psychiatrist, psychologist, social worker), human service (i.e. social services agency, religious counsellor) or complementary/alternative practitioners. Approximately half of all patients were seen in two treatment sectors, as indicated by the sum of treatment percentages across sectors being roughly one and a half times the number of cases that received any treatment.

The proportion of respondents with PD who were in treatment was higher (not significantly) than that of demographically matched respondents without PD (see model I, table 8). Adjusting for co-morbid axis I disorders did not alter this proportion significantly (see model II, table 8).

\section{Discussion}

The SASH study found that $6.8 \%$ of South Africans suffer from a DSM-IV PD. Although this rate is lower than most studies in the developed world, it is consistent with findings in Australia [25], as well as those in lowand middle-income countries, i.e. Brazil and China [26, 27]. The difference in prevalence might be explained by the use of different methodologies; however, the rate reported here is also lower than the $9 \%$ prevalence rate documented in the US [18], where a similar methodology was used. Differences in prevalence rates between countries could also be attributable, in part, to cultural, financial and economic development differences between countries.

Estimates of the prevalence of individual PD in previous US and British community studies have not been altogether consistent. Lenzenweger et al. [18] and Coid et al. [24] found cluster $C$ to be most prevalent followed by clusters A and B. Samuels et al. [19] found cluster B to be most prevalent, followed by clusters $\mathrm{C}$ and $\mathrm{A}$. In this study cluster A was found to be most prevalent (3.4\%), followed by cluster C (2.5\%). Cluster B was the least prevalent (1.5\%). Although this differs from the aforementioned studies, the rate of cluster B PD is similar to the rate of $1.5 \%$ documented by [18]. Our findings that cluster A PD are the most prevalent of the PD and cluster B PD are the least prevalent is interesting, in view of the finding that cluster A PD are the least frequently seen in clinical populations (owing to lower treatment-seeking behaviour in this subtype) and cluster B PD the most frequently seen [16].

In line with earlier findings [33], all PD clusters were significantly associated with the others: cluster A and B PD were most closely associated, followed by clusters A and $\mathrm{C}$, and lastly clusters B and C. Our findings also suggest that PD are highly co-morbid with axis I disorders in 
the South African population - 36.2\% of individuals with a PD also meet criteria for an axis I disorder, and $14.5 \%$ meet the criteria for more than one axis I disorder. This co-morbidity is broadly consistent with the results of previous clinical $[4,5,16]$ and epidemiological $[18]$ studies. In this study, PD was associated with all four axis I disorders, with the relationship with anxiety being the strongest.

Our results are consistent with findings of Samuels et al. [19] and Lenzenweger et al. [18], who found that cluster B PD are most likely to be co-morbid with axis I disorders. Depue and Lenzenweger $[34,35]$ note that this could be because the dysregulation in the underlying negative affect and constraint systems, which governs the erratic and impulsive symptoms of cluster B PD, might be a more important determinant of axis I disorders than clusters A or C. In addition, consistent with earlier studies, we found little differentiation in the strength of the associations between cluster $\mathrm{A}$ and $\mathrm{CPD}$ across the different axis I disorders. However, there was a great deal more variability in the associations between cluster B PD and axis I disorders, with substance use disorders having the strongest association. Thus, mechanisms underlying comorbidity of PD with axis I may be similar in both developed and developing world contexts as these seem to be universal relationships.

The absence of significant sociodemographic correlates of PD is noteworthy. Previous research has suggested that younger age, lower socio-economic status, male gender and being single, amongst others, are all predictors of PD. In our sample, only male gender was predictive of a PD, and in particular of cluster A PD. This is in line with a number of other studies, which have found that PD are generally more prevalent in men $[19,24]$. Although the preponderance of males may be due to the high rates of antisocial PD (cluster B), Samuels et al. [19] found more males to have both cluster A and B PD, and Coid et al. [24] found all PD to be more prevalent in males.

Disturbingly, only $19.9 \%$ of individuals diagnosed with a possible PD diagnosis in this community sample had received treatment for a mental health or substance problem in the previous twelve months. Although this is a higher percentage than that of the demographically matched respondents without $\mathrm{PD}$, it is lower than most studies in developed countries $[18,22,25]$. The majority of people with axis II disorders in the community are not receiving help for their disorders. This could be due to a lack of services or to a lack of awareness of these disorders in the community as well as in health care providers.
Some authors have pointed out that treatment seeking is related to a number of clinical and demographic factors $[36,37]$, including the presence of axis I disorders. Zimmerman et al. [16] suggest that PD as a group should be assessed in every patient since their presence can influence the course and treatment of presenting axis I disorders.

These results need to be interpreted in the context of the limitation that PD were assessed comprehensively only in a subsample of US respondents who received IPDE clinical reappraisal interviews. Clinical diagnoses were then imputed for the South African sample. Concern about this limitation is reduced by the fact that the AUC of imputation equations was consistently high. In addition, the MI method adjusts for the imprecision in parameter estimates introduced by imputation. Prevalence is estimated without bias with MI, whereas MI estimates of associations involving PD are conservative [18]. Thus, this study indirectly estimates the PD prevalence rate in this population, and as such the estimate of $6.8 \%$ is a conservative one.

A second limitation concerns the possibility that individuals with an axis I or II disorder might have been more likely to decline participation in this study, resulting in an underestimation of prevalence rates. However, our overall response rate was high and the data were weighted to account for underrepresentation of axis I disorders. Given the co-morbidity of axis I and axis II disorders, this methodological refinement might have helped to offset, in part, the non-participation of PD-affected individuals [18]. Nonetheless, it remains conceivable that these prevalence rates are somewhat underestimated. A third limitation is that the WMH-CIDI, in particular the personality disorders module, has not been validated in this population.

Within the context of these limitations, these findings emphasize that high co-morbidity with axis I disorders appears to be a universal phenomenon, and, given this, there is the possibility that PD affect the onset, persistence and severity of co-morbid axis I disorders, and may complicate their treatment. However, our finding that cluster $\mathrm{A}$ disorders are more prevalent than clusters $\mathrm{B}$ and $\mathrm{C}$ disorders is unusual and further work is needed to determine what local features might help to explain these data. Nonetheless, these findings contribute to our current understanding of the epidemiology of PD across cultures and stages of industrial and economic development. 


\section{Acknowledgements}

The SASH study was carried out in conjunction with the World Health Organization World Mental Health (WMH) Survey Initiative. We thank the WMH staff for assistance with instrumentation, fieldwork and data analysis. These activities were supported by the United States National Institute of Mental Health (R01MH070884), the John D. and Catherine T. MacArthur Foundation, the Pfizer Foundation, the US Public Health Service (R13-MH066849, R01-MH069864 and R01 DA016558), the Fogarty International Center (FIRCA R01-TW006481), the Pan American Health Organization, Eli Lilly and Company, Ortho-McNeil Pharmaceutical, GlaxoSmithKline and Bristol-Myers Squibb. The SASH study was funded by grant R01-MH059575 from the National Institute of Mental Health and the National Institute of Drug Abuse with supplemental funding from the South African Department of Health and the University of Michigan. Dan Stein and Soraya Seedat are also supported by the Medical Research Council of South Africa.

\section{References}

-1 Nestadt G, Romanosky AJ, Samuels JF, Folstein MF, McHugh PR: The relationship between personality and DSM-III axis I disorders in the population: results from an epidemiological survey. Am J Psychiatry 1992;149:1228-1233.

-2 Oldham JM, Skodel AE, Kellman HD, Hyler SE, Doidge N, Rosnick L, Gallaher PE: Comorbidity of axis I and axis II disorders. Am J Psychiatry 1995;152:571-578.

$\checkmark 3$ Goodwin RD, Brooks JS, Cohen P: Panic attacks and the risk of personality disorder. Psychol Med 2005;35:227-235

$\checkmark 4$ Johnson JG, Cohen P, Kasen S, Brook JS: Personality disorder traits associated with risk for unipolar depression during middle adulthood. Psychiatry Res 2005;136:113-121.

5 Bland RC, Stebelsky G, Orn H: Psychiatric disorders and unemployment in Edmonton. Acta Psychiatr Scandinavia 1988;77:72-80.

6 Johnson JG, Cohen P, Smailes E, Kasen S, Oldham JM, Skodol AE, Brook JS: Adolescent personality disorders associated with violence and criminal behaviour during adolescence and early adulthood. Am J Psychiatry 2000;157:1406-1412.

7 Mcranie EW, Kahan J: Personality and multiple divorce: a prospective study. J Nerve Ment Dis 1986;174:161-164.

8 Blackshaw L, Levy A, Perciano J: Listening to High Utilizers of Mental Health Services: Recognizing, Responding to and Recovering from Trauma. Salem, Office of Mental Health Services, 1999.

9 Massion AO, Dyck IR, Shea MT, Phillips KA, Warshaw MG, Keller MB: Personality disorders and time to remission in generalized anxiety disorder, social phobia, and panic disorder. Arch Gen Psychiatry 2002;59:434440 .

-10 Skodol AE, Oldham JM, Gallaher PD: Axis II comorbidity of substance use disorders among patients referred for treatment for personality disorders. Am J Psychiatry 1999; 156:733-738.
11 Grant BF, Hasin DS, Stinson FS, Dawson DA, Chou SP, Ruan WJ, Huang B: Co-occurrence of 12-month mood and anxiety disorders and personality disorders in the US: results from the national epidemiological survey on alcohol and related conditions. J Psychiatr Res 2005;39:1-9.

12 Grant BF, Hasin DS, Stinson FS, Dawson DA, Chou SP, Ruan WJ, Pickering RP: Prevalence, correlates, and disability of personality disorders in the United States: results from the National Epidemiological Survey on Alcohol and Related Conditions. J Clin Psychiatry 2004;65:948-958.

13 Winship G, Hardy S: Perspectives on the prevalence and treatment of personality disorder. J Psychiatr Ment Health Nurs 2007;14: 148-154.

14 Fridell M, Hesse M: Clinical diagnosis and SCID-II assessment of DSM-III-R personality disorders. Eur J Psychol Assess 2006;22: 104-108.

15 Sanderson WC, Wetzel S, Beck AT, Betz F: The prevalence of personality disorders among patients with anxiety disorders. Psychiatry Res 1994;51:167-174.

16 Zimmerman M, Rothschild L, Chelminsky I: The prevalence of DSM-IV personality disorders in psychiatric outpatients. Am J Psychiatry 2005;162:1911-1918.

17 Lenzenweger MF, Loranger AW, Korfine L, Neff C: Detecting personality disorders in a nonclinical population: application of a 2 stage procedure for case identification. Arch Gen Psychiatry 1997;54:345-351.

18 Lenzenweger MF, Lane MC, Loranger AW, Kessler RC: DSM-IV personality disorders in the National Comorbidity Survey Replication. Biol Psychiatry 2007;62:553-564.

-19 Samuels J, Eaton WO, Bienvenu OJ, Brown $\mathrm{CH}$, Costa PT, Nestadt G: Prevalence and correlates of personality disorders in a community sample. Br J Psychiatry 2002;180: 536-542.

20 Crawford TN, Cohen P, Johnson JG, Kasen S, First MB, Gordon K, Brook JS: Self-reported personality disorder in the children in the community sample: convergent and prospective validity in late adolescence and adulthood. J Personal Disord 2005;19:30-52.
-21 Maier W, Lichtermann D, Klinger T, Heun R, Hallmayer J: Prevalences of personality disorder (DSM-III-R) in the community. J Personal Disord 1992;6:187-196.

22 Ekselius L, Tillfors M, Furmark T, Fredrikson $\mathrm{M}$ : Personality disorders in the general population: DSM-IV and ICD-10 defined prevalence as related to sociodemographic profile. Pers Individ Dif 2001;30:311-320.

23 Torgersen S, Kringlen E, Cramer V: The prevalence of personality disorders in a community sample. Arch Gen Psychiatry 2001; 58:521-616

-24 Coid J, Yang M, Tyrer P, Roberts A, Ullrich $S$ : Prevalence and correlates of personality disorder in Great Britain. Br J Psychiatry 2006; 188:423-431.

$>25$ Jackson HJ, Burgess PM: Personality disorders in the community: results from the Australian National Survey of Mental Health and Wellbeing. II. Relationships between personality disorder, Axis I mental disorders and physical conditions with disability and health consultations. Soc Psychiatry Psychiatr Epidemiol 2002;37:251-260.

26 Rodrigues Torres A, Del Porto JA: Comorbidity of obsessive-compulsive disorder and personality disorders: a Brazilian controlled study. Psychopathology 1995;28:322-329.

-27 Huang Y, Liu B, Liu Z, Zhang G, Zhang H: A cross-sectional study of personality dysfunction among students of first-grade senior high schools in Beijing. Zhonghua Liu Xing Bing Xue Za Zhi 2002;23:338-340.

$>28$ El-Hosseiny WW, Mounir GM, Mahdy NH, Abu-Nazel MW: Predictors of personality disorders among Alexandria University Students. J Egypt Health Assoc 2004;79:115144.

29 Williams DR, Herman A, Kessler RC, Sonnega J, Seedat S, Stein DJ, Moomal H, Wilson CM: The South African Stress and Health Study: rationale and design. Metab Brain Dis 2004;19:135-147.

30 Kish L: A procedure for objective respondent selection within the household. J Am Stat Assoc 1949;44:380-387. 
-31 Kessler RC, Ustun TB: The World Mental Health (WMH) Survey Initiative version of the World Health Organization (WHO) Composite International Diagnostic Interview (CIDI). Int J Methods Psychiatr Res 2004;13:93-121.

32 Rubin DB: Multiple Imputation for Nonresponse in Surveys. New York, John Wiley and Sons, 1987.
33 McGlashan TH, Grilo CM, Skodol AE, Gunderson JG, Shea MT, Morey LC, Zanarini MC, Stout R: The Collaborative Longitudinal Personality Disorders Study: baseline Axis I/II and II/II diagnostic co-occurrence. Acta Psychiatr Scand 2000;102:256-264.

34 Depue RA, Lenzenweger MF: A neurobehavioral dimensional model of personality disorders; in Livesley WJ (ed): The Handbook of Personality Disorders. New York, Guilford, 2001.

35 Depue RA, Lenzenweger MF: A neurobehavioral model of personality disturbance; in Clarkin JF, Lenzenweger MF (eds): Major Theories of Personality Disorder, ed 2. New York, Guilford, 2005
6 Alegria M, Bijl RV, Lin E, Walters EE, Kessler RC: Income differences in persons seeking outpatient treatment for mental disorders: a comparison of the United States with Ontario and The Netherlands. Arch Gen Psychiatry 2002;57:383-391.

37 Goodwin RD, Hoven CW, Lyons SJ, Stein MB: Mental health service utilization in the United States: the role of personality disorders. Soc Psychiatry Psychiatr Epidemiol 2002;37:561-566. 